\title{
Preparation and Characterization of Magnetic Banana Peels Biochar for Fenton Degradation of Methylene Blue
}

\author{
Eric Sakué Ngankam1, Lemankreo Dai-Yang1, Baissassou Debina1, Abdellaziz Baçaoui², \\ Abdelrani Yaacoubi ${ }^{2}$, Abdoul Ntieche Rahman ${ }^{3 *}$ \\ ${ }^{1}$ Department of Chemistry, Faculty of Science, University of Maroua, Maroua, Cameroon \\ ${ }^{2}$ Department of Chemistry, Faculty of Science Semlalia, University of Cady Ayyad, Marrakech, Morocco \\ ${ }^{3}$ Department of Chemistry, Higher Teachers’ Training College of Bertoua, University of Ngaoundéré, Ngaoundéré, Cameroon \\ Email: ^rahmino@gmail.com
}

How to cite this paper: Ngankam, E.S., Dai-Yang, L., Debina, B., Baçaoui, A., Yaacoubi, A. and Rahman, A.N. (2020) Preparation and Characterization of Magnetic Banana Peels Biochar for Fenton Degradation of Methylene Blue. Materials Sciences and Applications, 11, 382-400.

https://doi.org/10.4236/msa.2020.116026

Received: October 25, 2019

Accepted: June 26, 2020

Published: June 29, 2020

Copyright $\odot 2020$ by author(s) and Scientific Research Publishing Inc. This work is licensed under the Creative Commons Attribution International License (CC BY 4.0).

http://creativecommons.org/licenses/by/4.0/

\section{(c) (i) Open Access}

\begin{abstract}
Co-precipitation method was used for the synthesis of biochar $/ \mathrm{Fe}_{3} \mathrm{O}_{4}$ to heterogeneously degrade methylene blue (MB) in an aqueous medium. This catalyst was characterized by different techniques such as Fourier Transform Infrared (FTIR) Spectroscopy, X-ray diffraction (XRD), Scanning Electron Microscopy (SEM), Energy Dispersive X-ray Spectroscopy (EDX) and Raman Microscopy. The analysis highlighted the presence of iron oxides on the surface of the biochar in the form of magnetite $\left(\mathrm{Fe}_{3} \mathrm{O}_{4}\right)$. Catalytic tests performed on this composite showed significant degradation and simple magnetic separation in the solution for reuse. Maximum degradation was carried out after stirring it for 90 minutes in an $\mathrm{MB}$ aqueous solution at different concentrations. The percentages of degradation were $99 \%$ and $98.6 \% 93.3 \%$ and $91 \%$ for concentrations of MB $40 \mathrm{mg} / \mathrm{L}$ and $60 \mathrm{mg} / \mathrm{L}, 80 \mathrm{mg} / \mathrm{L}$ and $120 \mathrm{mg} / \mathrm{L}$ respectively. The reactions followed a second-order kinetics with correlation coefficients $\mathrm{r}^{2}=$ $0.9598,0.9247,0.9548$ and 0.9614 for the same concentrations of $\mathrm{MB}$ at $\mathrm{pH}=2$, $0.2 \mathrm{~mL} / \mathrm{L} \mathrm{H}_{2} \mathrm{O}_{2}$ and $15 \mathrm{mg}$ of biochar $/ \mathrm{Fe}_{3} \mathrm{O}_{4}$. This work provides a simple and an effective method for the preparation of biochar/ $/ \mathrm{Fe}_{3} \mathrm{O}_{4}$ and its use for the oxidation of MB by means of heterogeneous Fenton.
\end{abstract}

\section{Keywords}

Co-Precipitation, Magnetic Separation, Composite, Heterogeneous Fenton

\section{Introduction}

Water pollution by dyes has become a concern for the world's population for decades. These dyes are listed in more than 100,000 types with an annual pollution 
of $7 \times 10^{5}$ tons. The textile industries are considered as major consumers with around 36,000 tons per year. The World Bank estimates that around $20 \%$ of dye pollution comes from dyeing and textile processing [1]. According to studies $50 \mathrm{~L}$ to $100 \mathrm{~L}$ of water are consumed to tint $1 \mathrm{~kg}$ of cotton [2]. Insufficient treatment of textile effluents can lead to their accumulation in the water cycle, which can affect people living either through direct consumption of polluted water or through the food chain.

Physical techniques including adsorption are used for the treatment of industrial wastewater, but they are limited to a simple transfer of the pollutant from the effluent to the adsorbent, without any degradation occurs. The Advanced Oxidation process (AOP) is the burgeoning method of the chemical treatment of organic contaminants, considered to be bio-recalcitrant and/or for the disinfection of emerging pathogens [3]. It is based on the formation of highly reactive oxidative species (free radicals ${ }^{\circ} \mathrm{OH}$ ) that can be induced by catalytic, sonochemical, biological, electrochemical and/or photochemical activations [4]. The high reactivity of the hydroxide radical with an oxidation potential of $+2.80 \mathrm{~V}(\mathrm{ESH})$, has the power to oxidize many organic and inorganic molecules leading to their mineralization [5] [6]. The mechanism of generation of ${ }^{\circ} \mathrm{OH}$ by the Fenton reactions has been taken up by Xuang and Kim (2018) according to the following equations:

$$
\begin{gathered}
\mathrm{Fe}(\mathrm{II})+\mathrm{H}_{2} \mathrm{O}_{2} \rightarrow \mathrm{Fe}(\mathrm{III})+{ }^{\circ} \mathrm{OH}+\mathrm{OH}^{-} \\
\mathrm{Fe}(\mathrm{III})+\mathrm{H}_{2} \mathrm{O}_{2} \rightarrow \mathrm{Fe}\left(\mathrm{HO}_{2}\right)^{2+}+\mathrm{H}^{+} \\
\mathrm{Fe}\left(\mathrm{HO}_{2}\right)^{2+} \rightarrow \mathrm{Fe}(\mathrm{II})+\mathrm{HO}_{2} \\
\mathrm{O}^{2-}+\mathrm{Fe}(\mathrm{III}) \rightarrow \mathrm{Fe}(\mathrm{II})+\mathrm{O}_{2} \\
{ }^{\circ} \mathrm{OH}+\mathrm{H}_{2} \mathrm{O}_{2} \rightarrow \mathrm{HO}_{2}+\mathrm{H}_{2} \mathrm{O}
\end{gathered}
$$

Unlike the homogeneous Fenton method using iron ion and hydrogen peroxide, the heterogeneous $\mathrm{Fe}_{3} \mathrm{O}_{4}$ method is increasingly used because it is easy to recover in a solvent using a magnetic field and can be regenerated for multiple uses [7] [8] [9].

To increase the catalytic activity of $\mathrm{Fe}_{3} \mathrm{O}_{4}$, it is more and more immobilized in porous supports. Biochar [9] [10]; clay [11]; activated carbon [12] [13] [14], carbon microspheres [5], graphenes [15] [16], multi-walled carbon nanotube [17] are the most used because of their small sizes, the hydrophilic groups on their surfaces, their thermal stability as well as their ease in being dispersed in water. Biochar is used as an excellent platform to support various catalytic nanoparticles due to its unique surface properties, easily adjustable functional groups, chemical stability and electrical conductivity [18]. It is considered a reservoir of electrons, and the quinone groups on the surface facilitate electronic exchanges during catalysis [19] [20]. Banana peel is used for the preparation of biochar by its abundance. In 2016, Cameroon was considered the first banana producer in Africa. Therefore, it has been proved banana peels equivalent to $40 \%$ of the total weight of fresh ba- 
nana, are generated as a wasted product in industries producing banana products [21]. These peels are not being used for any other purposes and or mostly dumped as solid waste at large expense; hence the need to transform it into biochar and use it as a catalytic support. We now count several methods of immobilization of $\mathrm{Fe}_{3} \mathrm{O}_{4}$ of magnetism on a biochar support, namely the co-precipitation technique, the hydrothermal method, ball mill method; the sol gel method [22] [23] [24]. The co-precipitation method is the one most used because it is easy to implement that and it takes place at low temperature. The coprecipitation method has the advantage of directly obtaining homogeneous nanomaterials with small size and size distribution through various chemical reactions in the solution. The main advantage is that a large quantity of nanoparticles material can be produced. The coprecipitation technique is probably the simplest and most convenient chemical pathway to synthesize magnetic nanoparticles [25].

In this work, the biochar from the dry banana peels was prepared by simple pyrolysis under nitrogen atmosphere and the co-precipitation method was used for the immobilization of magnetite used as precursors $\mathrm{FeCl}_{2} \cdot 4 \mathrm{H}_{2} \mathrm{O}$ and $\mathrm{FeCl}_{3} \cdot 6 \mathrm{H}_{2} \mathrm{O}$. The catalyst prepared was characterized by Fourier transform infrared (FTIR), Raman spectroscopy, X-ray diffraction (XRD), Scanning electron microscopy (SEM), energy dispersive X-ray spectroscopy (EDX). The ability of the particles to facilitate the Fenton oxidation of methylene blue (MB) has been studied under conditions of $\mathrm{pH}$, pollutant concentration, agitation time, catalyst mass and very precise $\mathrm{H}_{2} \mathrm{O}_{2}$ concentration.

\section{Experimental Section}

\subsection{Reagents and Materials}

The "Musa" banana peels, collected in municipal garbage cans were washed, dried and used as precursors of char. Iron III chloride hexahydrate $\left(\mathrm{FeCl}_{3} \cdot 6 \mathrm{H}_{2} \mathrm{O}, 99 \%\right.$ purity) and iron II chloride tetrahydrate $\left(\mathrm{FeCl}_{2} \cdot 4 \mathrm{H}_{2} \mathrm{O} 99 \%\right.$ purity) was supplied by LaboChemie. Sodium Hydroxide $(\mathrm{NaOH}, \geq 99 \%$ purity) purchased from Sigma Aldrich. Hydrochloric acid ( $\mathrm{HCl} 37 \%)$ from CarloERBA. Ethanol $\left(\mathrm{CH}_{3} \mathrm{CH}_{2} \mathrm{OH}\right.$, 299\%) purchased from Sigma Aldrich. Hydrogen peroxide $\left(\mathrm{H}_{2} \mathrm{O}_{2}, 30.1 \%\right)$ from PROLABO. Methylene blue (MB, 98\%) of formula $\mathrm{C}_{16} \mathrm{H}_{18} \mathrm{ClN}_{3} \mathrm{~S}$ from Reactive RAL. All chemicals are analytical grade and were used without further purification.

\subsection{Preparation of Biochar $/ \mathrm{Fe}_{3} \mathrm{O}_{4}$}

Raw materials (ripe banana peels), collected in municipal garbage cans were washed, dried in the sun for 8 hours and then at $80^{\circ} \mathrm{C}$ in an oven for 24 hours. Later on, the samples were scrambled into small particles followed by the introduction of $15 \mathrm{~g}$ of obtained samples into the carbolite brand turbolace and their carbonization at $500^{\circ} \mathrm{C}$ under nitrogen $\mathrm{N}_{2}$ atmosphere $(0.15 \mathrm{~mL} / \mathrm{min})$ with a temperature change of $10^{\circ} \mathrm{C} / \mathrm{min}$ and a residence time of $2 \mathrm{~h}$. The oven was allowed to cool down to room temperature. The biochar was then recovered, dried in an oven during 24 hours and then stored.

The biochar $/ \mathrm{Fe}_{3} \mathrm{O}_{4}$ was prepared by co-precipitation method as described by 
Monica et al. [13]: $2 \mathrm{~g}$ of biochar previously prepared were introduced in $200 \mathrm{~mL}$ of an aqueous solution containing $7.32 \mathrm{~g}$ of $\mathrm{FeCl}_{3} \cdot 6 \mathrm{H}_{2} \mathrm{O}(27 \mathrm{mM})$ and 2, $67 \mathrm{~g}$ of $\mathrm{FeCl}_{2} \cdot 4 \mathrm{H}_{2} \mathrm{O}(13.5 \mathrm{mM})$ (Fer III/Fer II ratio 2: 1) under magnetic stirring at $80^{\circ} \mathrm{C}$; $50 \mathrm{~mL}$ of $\mathrm{NaOH}$ solution $(5 \mathrm{M})$ was added while maintaining the temperature $80^{\circ} \mathrm{C}, \mathrm{pH}(10-12)$. The suspension was stirred for about 1 hour until the color changed from the brown to black color. The whole left at room temperature was filtered and the precipitate was washed several times with distilled water and ethanol to neutral $\mathrm{pH}$. The obtained sample was dried at $80^{\circ} \mathrm{C}$ and stored for physico-chemical characterizations. Pure magnetite was prepared by the same procedure in the absence of biochar.

\subsection{Characterization of the Catalyst}

The $\mathrm{pH}$ of zero charge was determined as follows: $50 \mathrm{~mL}$ of an aqueous solution of $\mathrm{NaCl}(0.01 \mathrm{M})$ were introduced into six $\mathrm{pH}$ bottles; the $\mathrm{pH}$ was adjusted to 2 , 4, 6, 8 and 10. These different bottles were bubbled with nitrogen to stabilize the pH. $0.15 \mathrm{~g}$ of Biochar $/ \mathrm{Fe}_{3} \mathrm{O}_{4}$ was introduced into these different flasks. The mixtures, stirred during 48 hours were filtered and the final $\mathrm{pH}$ of the filtrate was measured using a $\mathrm{pH}$ meter (HI $2209 \mathrm{pH}$ meter). The encounter with the first bisector of the $\mathrm{pH}$ curve (final) $=\mathrm{f}$ (initial $\mathrm{pH}$ ) indicates the $\mathrm{pH}$ of charge zero charge [26]. Similarly, the $\mathrm{pH}$ of the material was carried out using $0.15 \mathrm{~g}$ Biochar $/ \mathrm{Fe}_{3} \mathrm{O}_{4}$ in $50 \mathrm{~mL}$ of distilled water, stirred for $48 \mathrm{~h}$ and measuring the $\mathrm{pH}$.

The functional groups present in Biochar $/ \mathrm{Fe}_{3} \mathrm{O}_{4}$ were ascertained by Fourier transform Infrared spectroscopy (FTIR, Vertex 70 de BRUKER) over the region $400-4000 \mathrm{~cm}^{-1}$ in pellet form the powder samples of $1 \mathrm{mg}$ mixed with spectroscopic grade $\mathrm{KBr}$ (Merck) of $9 \mathrm{mg}$ with a resolution of $4 \mathrm{~cm}^{-1}$ (32 scans). Spectra $\mathrm{X}$-ray diffraction on XRD powder (RigakuGeigerflex, $\mathrm{Cu} \mathrm{K} \alpha, \lambda=1.5406 \mathrm{~A}$ ) produced at $30 \mathrm{kV}$ and $25 \mathrm{~mA}$ scanned the diffraction angles $(2 \theta)$ between $10^{\circ}$ and $80^{\circ}$ with the step size of $0.002^{\circ} 2 \theta$ per second. Elemental EDX analysis performed using EDAX TEAM, $125.9 \mathrm{ev}$ of resolution, to know the composition of the elements present in the material as well as SEM (VEGA3 TESCAN) to know the surface morphology. Raman spectroscopy to determine the structural and electronic properties of materials performed with a Nano brand SP (Confotec MR-SOL instrument) with the $570 \mathrm{~nm}$ wavelength laser. All these analyzes were carried out at the "Centre d'Analyseet de Caractérisation" Semlalia-Marrakech Faculty of Sciences of Cadi Ayyad University (Morocco).

\subsection{Experimental Procedure}

To evaluate the catalytic activity of the material, an aqueous solution of methylene blue at the concentrations of $40 \mathrm{mg} / \mathrm{L}$ and $60 \mathrm{mg} / \mathrm{L}, 80$ and $120 \mathrm{mg} / \mathrm{L}$ were used. $15 \mathrm{mg}$ of the catalyst was added to $50 \mathrm{~mL}$ of the $\mathrm{MB}$ solution, $\mathrm{pH}=2.0 .2$ $\mathrm{mL} / \mathrm{L}$ of hydrogen peroxide $\left(\mathrm{H}_{2} \mathrm{O}_{2}\right)$ was added to the $\mathrm{MB}$ solution. The whole solution was stirred for $90 \mathrm{~min}$ and after the solid phase was separated from liquid one by magnetization (Figure 1). The residual concentration of MB was measured by means of SECOMAN brand UV-Vis spectrometer. 


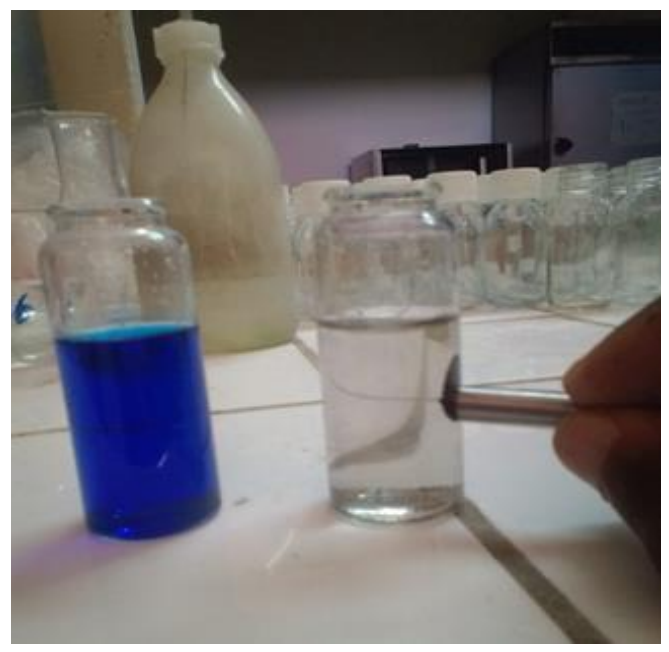

Figure 1. Separation of biochar $/ \mathrm{Fe}_{3} \mathrm{O}_{4}$ from the rest of the liquid solution by a magnet.

The MB degradation percentage was calculated using the following formula

$$
\% R=\frac{\left(C_{o}-C_{e}\right) \cdot 100}{C_{o}}
$$

$C_{o}$ is the initial concentration of $\mathrm{MB}(\mathrm{mg} / \mathrm{L}) ; C_{e}$ is the concentration at any time $(\mathrm{mg} / \mathrm{L})$ and $\% R$ is the percentage of elimination of $\mathrm{MB}(\%)$. Kinetic studies were performed and the equations corresponding to the different orders are given by the formulas [27]:

The kinetics of the zero order, is given by Equation (6)

$$
[M B]_{i}-[M B]_{t}=k_{o} t
$$

The first order is given by Equation (7)

$$
-\ln \left(\frac{[M B]_{t}}{[M B]_{i}}\right)=K_{2} t
$$

with $[M B]_{i}$ and $[M B]_{t}$ the concentrations $t=0$ and $t=t$ respectively, $k$ is the speed constant $\left(\mathrm{min}^{-1}\right)$ and $t$ the time ( $\left.\mathrm{min}\right)$.

The second order is given by Equation (8)

$$
\frac{1}{[M B]_{t}}-\frac{1}{[M B]_{i}}=K_{2} t
$$

\section{Results and Discussion}

\subsection{Characterization}

Fourier transform infrared spectrum (FTIR) is done to determine the structural characterization of the dry banana peels, biochar and biochar $/ \mathrm{Fe}_{3} \mathrm{O}_{4}$. Figure 2 shows the FTIR spectra of the banana peels, biochar and biochar $/ \mathrm{Fe}_{3} \mathrm{O}_{4}$ in wave number range of $4000-400 \mathrm{~cm}^{-1}$. 
Some characteristic bands from dry banana peels disappeared for the benefit of others bands. The wide band around $3500-3250 \mathrm{~cm}^{-1}$ attributable to the $-\mathrm{OH}$ stretching vibrations. This band reappears intensely when magnetite is introduced; due to the fact that the impregnation reaction is carried out in an aqueous medium (co-precipitation). The bands around $1583.4-1635 \mathrm{~cm}^{-1}$ attributed to the elongation vibrations of $\mathrm{C}=\mathrm{O}, \mathrm{C}=\mathrm{C}$ functions remained unchanged and having almost the same intensities on the dried banana peel as on the calcined and magnetized peel. Just a decrease in the intensity of the peaks (on banana peel calcined at $500^{\circ} \mathrm{C}$ ) due to pyrolysis. The presence of $\mathrm{O}-\mathrm{H}$ deformation bond is observed at $1300 \mathrm{~cm}^{-1}$. We observe the $\mathrm{C}-\mathrm{O}$ stretching vibration band at 1053 $\mathrm{cm}^{-1}$ with a higher intensity on the black curve. Two bands, one very intense (650 $567 \mathrm{~cm}^{-1}$ ) and the other less intense $\left(444 \mathrm{~cm}^{-1}\right)$ are observed and respectively corresponded to iron oxides (Fe-O) and oxides iron and silica (Fe-O-Si) [28] [29] revealed that the band between $450-740 \mathrm{~cm}^{-1}$ belonged to the $\mathrm{Fe}-\mathrm{O}$ vibrations of the nanoparticles of iron oxides. We have in this case the chemical shifts towards the high wavelengths (hypochromic effect) of the probably biochar which thanks to its surface rich in electrons, has the capacity to reduce the gap energy of the semiconductors thus causing an increase its chemical shift [30].

Raman spectroscopy is a non-destructive method used to characterize the structural and electronic properties of materials. Figure 3 is the Raman analysis curves for our biochar and biochar $/ \mathrm{Fe}_{3} \mathrm{O}_{4}$ samples.

The Raman spectra of the biochar from the banana peels (Figure 3(a)) have several bands, three of which are larger and have corresponding chemical shifts. The band at $1567 \mathrm{~cm}^{-1}$ corresponding to the band $\mathrm{G}$ ( $\mathrm{G}$ = graphite) of the $\mathrm{E}_{2} \mathrm{~g}$ mode of hexagonal graphite. It is related to the vibration involving $\mathrm{sp}^{2}$ of hybrid carbon atoms that includes graphene sheet [31] [32]. This position of the peak G indicates the degree of charge transfer. Due to the stiffness of G-peak related links, the phonon mode energy increases [33]. On the other hand, when we mix the biochar with the iron oxides, the Raman spectrum (Figure $3(\mathrm{~b})$ ) indicates the very weak $G$ band $\left(I_{D} / I_{G}=2.4\right)$. This low intensity as well as the $I_{D} / I_{G}$ ratio shows that iron oxides create a lot of disorder in the biochar structure.

Band D ( $\mathrm{D}=$ disorder) at about $1372.2 \mathrm{~cm}^{-1}$ (Figure $3(\mathrm{a})$ ) is known as the disorder or defect band and represents a carbon ring breathing pattern sp2, although to be active the ring must be adjacent to a graphene edge or defect. Its intensity is much greater in our material (Figure $3(\mathrm{a})$ ) and the ratio $\mathrm{I}_{\mathrm{D}} / \mathrm{I}_{\mathrm{G}}=0.98$ thus confirms the defect in the carbon structure. The presence of defects improves the performance of carbon materials because of the strong anisotropy, mechanical strength, or electrical conductivity between the plane and out-of-plane direction [34]. On the spectrum in Figure 3(b) we observe a weak intensity as well as a Raman shift towards the low wavelengths $\left(1291.3 \mathrm{~cm}^{-1}\right)$. This decrease is accompanied by the absence of band G.In the end the strongest and most intense band covers an area between $2400 \mathrm{~cm}^{-1}$ and $3300 \mathrm{~cm}^{-1}$ at is the 2D band. This band has no defect and is still used to determine the thickness of the graphene layer. This is one of the characteristic bands of grapheme. 


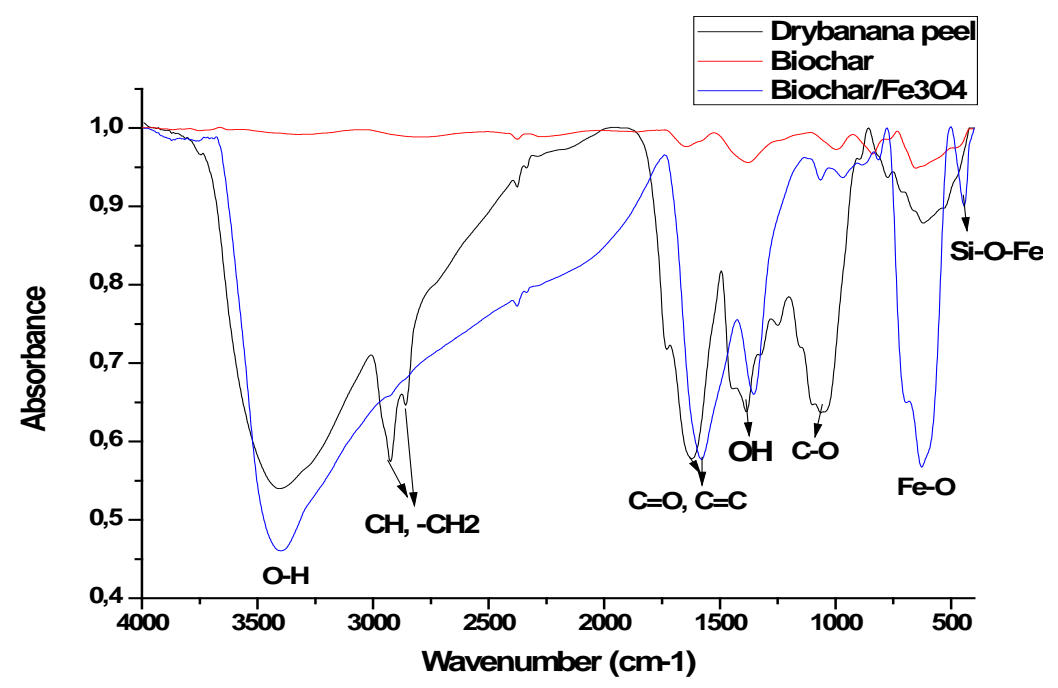

Figure 2. IR spectrum of biochar $/ \mathrm{Fe}_{3} \mathrm{O}_{4}$.

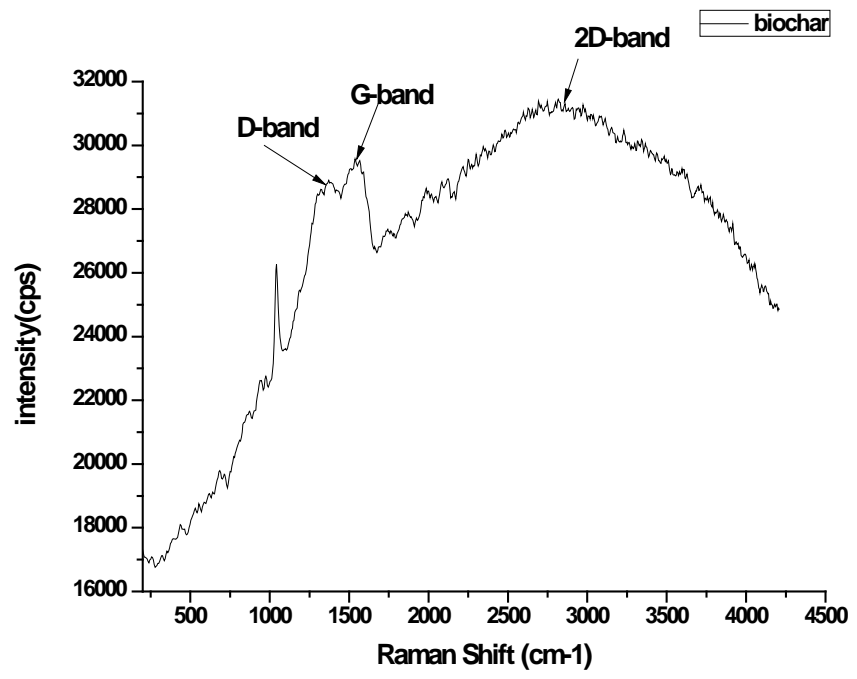

(a)

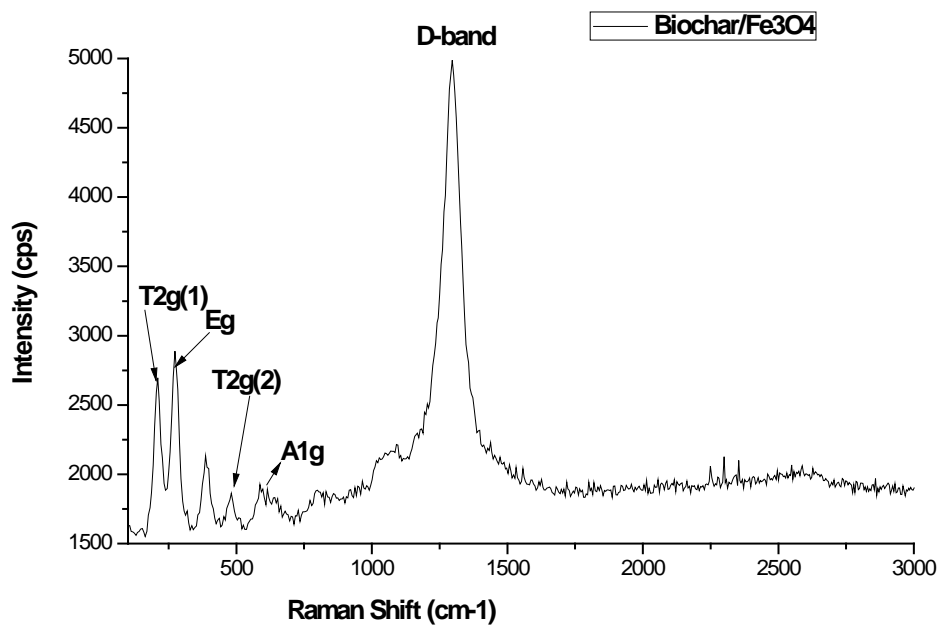

(b)

Figure 3. Raman spectra of the biochar (a) and biochar/ $/ \mathrm{Fe}_{3} \mathrm{O}_{4}(\mathrm{~b})$. 
Some bands absent on the spectrum Figure 3(a) are present in Figure 3(b) between $200 \mathrm{~cm}^{-1}$ and $1050 \mathrm{~cm}^{-1}$. These bands are $209.8 \mathrm{~cm}^{-1}$ respectively; 278.5 $\mathrm{cm}^{-1} ; 391.75 \mathrm{~cm}^{-1} ; 481.5 \mathrm{~cm}^{-1}$ and $603 \mathrm{~cm}^{-1}$. The band observed at $603 \mathrm{~cm}^{-1}$ is assigned to the $A_{1} g$ mode which provides the stretching vibration of the oxygen atoms along the $\mathrm{Fe}-\mathrm{O}$ bonds [35]. This expected band around $590 \mathrm{~cm}^{-1}$ moves towards the strong wavelengths of the biochar. The bands around $209.8 \mathrm{~cm}^{-1}$; $278.5 \mathrm{~cm}^{-1} ; 481.5 \mathrm{~cm}^{-1}$ corresponds to $\mathrm{T}_{2 \mathrm{~g}}(1)$ asymmetric Fe-O bonding mode; $\mathrm{E}_{\mathrm{g}}$ symmetrical Fe-O and $\mathrm{T}_{2 \mathrm{~g}}$ (2) symmetrical $\mathrm{Fe}-\mathrm{O}$ stretch band of magnetite. We have at the end a $1090 \mathrm{~cm}^{-1}$ band that could be a harmonic band of maghemite melted into magnetite [36].

The SEM/EDX analyze of the carbonized material and the magnetized materials are represented by Figure 4 .

The SEM image of biochar Figure 4(a) showed a porous surface due to the carbonization process which favored the development of the porosity of materials. The SEM image of the magnetized banana peels Figure 4(c) showed a surface filled with cavity resulting from the pyrolysis of the banana peels at $500^{\circ} \mathrm{C}$. However, it is covered with iron oxides which obstruct these cavities. The presence of pores in the form of a cavity on the surface of a material is favorable to the adsorption of iron particles during the synthesis process as shown in Figure 4(c) [13] [14].

The elemental and semi-quantitative composition of the biochar and the catalyst (Biochar $/ \mathrm{Fe}_{3} \mathrm{O}_{4}$ ) are represented on the EDX spectra in Figure 4(b) and Figure 4(d) and the summary is shown in Table 1. We observe on the EDX spectrum, the variation of the percentage $(\mathrm{C}, \mathrm{O}, \mathrm{Al}, \mathrm{Si}, \mathrm{P}, \mathrm{Cl})$, the disappearance of elements $(\mathrm{K}, \mathrm{Mg})$ and the appearance of the new elements $(\mathrm{Fe}, \mathrm{N})$ after impregnation of magnetite. The presence of various elements even after impregnation of magnetite, informe us about the impure nature of Biochar/ $/ \mathrm{Fe}_{3} \mathrm{O}_{4}$.

$\mathrm{X}$-Ray Diffraction is an indispensable technique for identifying the crystalline phases of a compound. It is based on the observation of constructive interferences starting from a monochromatic radiation of wavelength $\lambda$ using Bragg's law:

$$
2 d \sin \theta=n \lambda .
$$

where: $\theta$ is the diffraction angle and the area under the peak is proportional to the diffracted intensity; $d$ : distance between the crystalline plane; $n$ : diffraction order.

The position of the peaks in the diagram corresponds to the angle $2 \theta$.

The X-ray diffraction spectra of our two materials are shown in Figure 5.

The biochar curve powder diffractogram (black) showed several peaks, one of which is stronger and the others are not excessively good. This makes us understand that more than $80 \%$ of the carbon structure is amorphous. This tells us that pyrolysis at $500^{\circ} \mathrm{C}$ of banana peel is not complete and that amorphous carbon still exists. According to the position of the peaks, the banana peel would be thermally decomposed Fullerene and chaolite. Peaks $2 \theta=11.4^{\circ}$ and $31.7^{\circ}$ are those of fullerenes and those at $2 \theta=23.06^{\circ} ; 28.34^{\circ} ; 30.7^{\circ} ; 31.62^{\circ} ; 37.92^{\circ}$ and $40.58^{\circ}$ are attributed to chaolite [37]. On the other hand, according to Li et al. (2007), the more intense peak at $2 \theta=28.34$ could be the turbostratic structure of graphite carbon. 


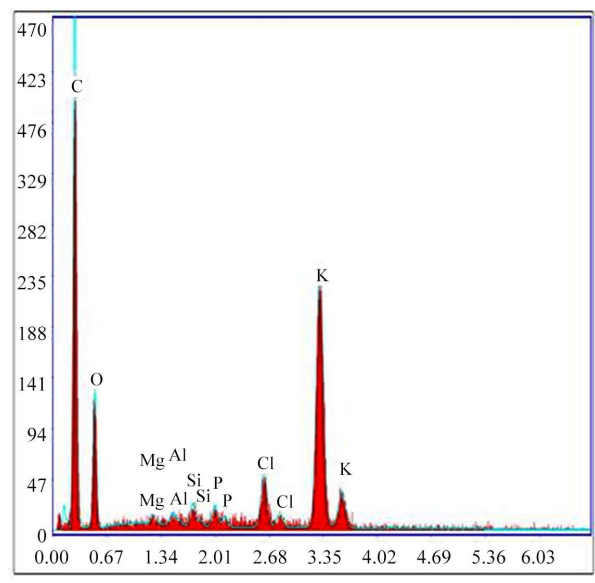

Lsec: 50.0 8Cnts $1.610 \mathrm{keV}$ Det: Octane Plus

(a)

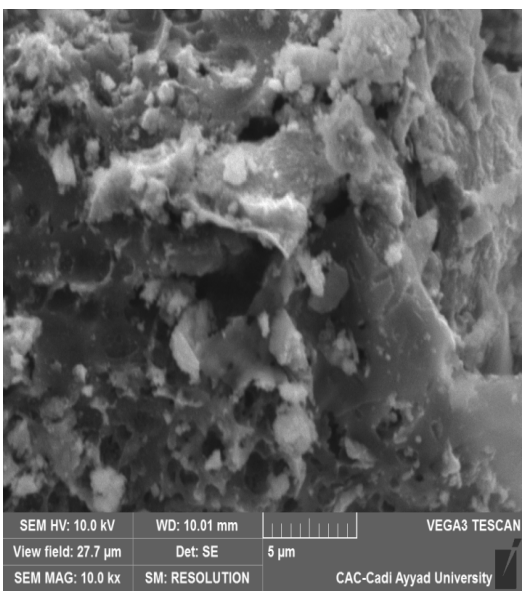

(c)

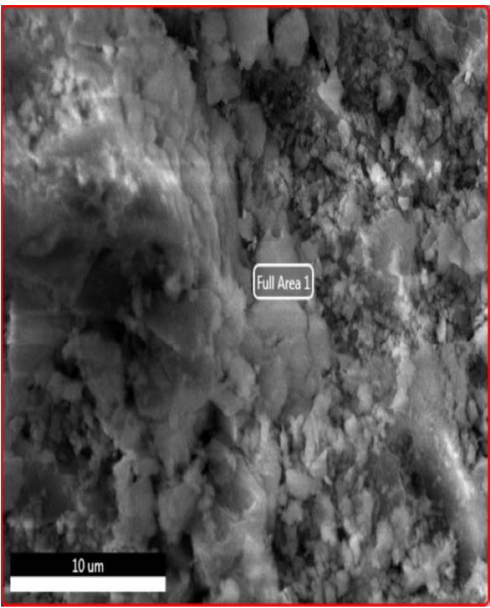

(b)

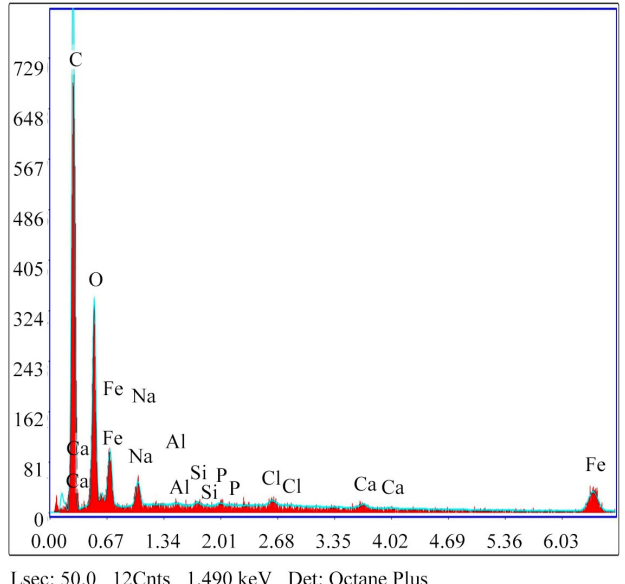

(d)

Figure 4. Scanning Electron Microscopy (SEM) and EDX biochar (a, b) and biochar/ $/ \mathrm{Fe}_{3} \mathrm{O}_{4}$ (c, d).

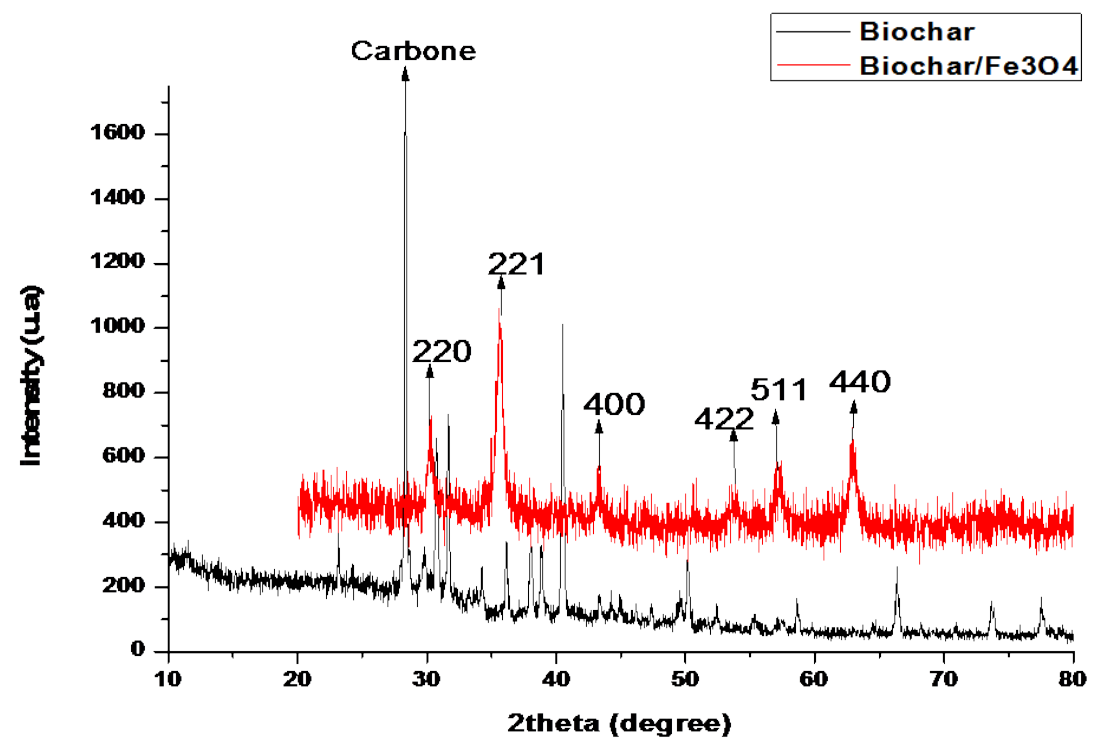

Figure 5. XRD Curves of biochar (Black) and Biochar/ $/ \mathrm{Fe}_{3} \mathrm{O}_{4}$ (Red). 
Table 1. Elemental composition of biochar and biochar $/ \mathrm{Fe}_{3} \mathrm{O}_{4}$ catalysts.

\begin{tabular}{|c|c|c|c|c|c|c|c|}
\hline Material & Element & Weight (\%) & Atomic (\%) & Material & Element & Weight (\%) & Atomic (\%) \\
\hline \multirow{10}{*}{ Biochar } & $\mathrm{C}$ & 31.26 & 52.37 & \multirow{10}{*}{ Biochar $/ \mathrm{Fe}_{3} \mathrm{O}_{4}$} & $\mathrm{C}$ & 52.61 & 66.58 \\
\hline & $\mathrm{O}$ & 15.19 & 19.10 & & $\mathrm{O}$ & 27.75 & 26.36 \\
\hline & $\mathrm{Mg}$ & 0.44 & 0.36 & & $\mathrm{Fe}$ & 13.02 & 3.54 \\
\hline & $\mathrm{Al}$ & 0.48 & 0.36 & & $\mathrm{Al}$ & 0.17 & 0.09 \\
\hline & $\mathrm{Si}$ & 1.16 & 0.83 & & $\mathrm{Si}$ & 0.39 & 0.21 \\
\hline & $\mathrm{P}$ & 1.44 & 0.94 & & $\mathrm{P}$ & 0.47 & 0.23 \\
\hline & $\mathrm{Cl}$ & 5.62 & 3.19 & & $\mathrm{Cl}$ & 1.02 & 0.44 \\
\hline & K & 44.41 & 22.85 & & $\mathrm{Ca}$ & 1.70 & 0.64 \\
\hline & $\mathrm{N}$ & 0 & 0 & & $\mathrm{~N}$ & 2.88 & 1.90 \\
\hline & Total & 100 & 100 & & Total & 100 & 100 \\
\hline
\end{tabular}

On the spectrum of biochar $/ \mathrm{Fe}_{3} \mathrm{O}_{4}$ (red), the diffraction peaks are present at $2 \theta=$ $30.2^{\circ}, 35.7^{\circ}, 43.3^{\circ}, 53.7^{\circ}, 57.2^{\circ}, 62.9^{\circ}$ correspond to the indices (220) (221) (400) (422) (511) (440) which are the inverse spinel group (Fd-3m) of magnetite according to the literature [37] [38]. A peak at $2 \theta=26.8^{\circ}$ would belong to quartz grain crystals $\left(\mathrm{SiO}_{2}\right)$ according to $\mathrm{He}$ et al. [10].

\subsection{Catalytic Activities}

The degradation of $\mathrm{MB}$ was studied by various processes namely homogeneous Fenton $\left(\mathrm{Fe}_{3} \mathrm{O}_{4} / \mathrm{H}_{2} \mathrm{O}_{2}\right)$, adsorption (Biochar, $\mathrm{Fe}_{3} \mathrm{O}_{4}$ and Biochar $/ \mathrm{Fe}_{3} \mathrm{O}_{4}$ ), and finally heterogeneous Fenton (Biochar $/ \mathrm{Fe}_{3} \mathrm{O}_{4} / \mathrm{H}_{2} \mathrm{O}_{2}$ ) in a solution of $80 \mathrm{mg} / \mathrm{L}(\mathrm{MB})$ at $\mathrm{pH}=2$ (Figure 6), 90 minutes stirring and $0.2 \mathrm{ml} / \mathrm{L} \mathrm{H}_{2} \mathrm{O}_{2}$. The results indicated no degradation effect when $\mathrm{Fe}_{3} \mathrm{O}_{4}$ is used, low retention of (5\%) when introducing Biochar $/ \mathrm{Fe}_{3} \mathrm{O}_{4}$ and $15 \%$ for biochar alone. This weak adsorption (5\%) might be due to the occupation of the sites of adsorption of biochar by magnetite during synthesis on the one hand. On the other hand, the MB being a cationic pollutant, the adsorption in an acid medium is not favorable because of the electrostatic repulsions between the $\mathrm{MB}$ cation and the biochar surface $(\mathrm{pHzc}>\mathrm{pH}$ of the medium) possessing the same positive charge. When we introduce $\mathrm{H}_{2} \mathrm{O}_{2}$ alone there is no effect. Whereas, when we use $\mathrm{Fe}_{3} \mathrm{O}_{4} / \mathrm{H}_{2} \mathrm{O}_{2}$ in the methylene blue solution, we observe a degradation of $65.8 \%$ under the same conditions. This degradation is due to the generation of hydroxide radicals which leads to the oxidation of MB. The degradation reached its maximum at $93.3 \%$ (for $80 \mathrm{mg} / \mathrm{L}$ $\mathrm{MB}$ ) when passing to heterogeneous Fenton using Biochar $/ \mathrm{Fe}_{3} \mathrm{O}_{4} / \mathrm{H}_{2} \mathrm{O}_{2}$ as catalyst. This is due to the electron-rich biochar surface of quinone groups that facilitates electronic exchanges during catalysis [19] [20] [39].

The kinetic studies made on Biochar $/ \mathrm{Fe}_{3} \mathrm{O}_{4} / \mathrm{H}_{2} \mathrm{O}_{2}$ for the different concentrations of $\mathrm{MB}$ at $90 \mathrm{~min}, \mathrm{pH}=2,0.2 \mathrm{~mL} / \mathrm{L} \mathrm{H}_{2} \mathrm{O}_{2}, 15 \mathrm{mg}$ of the catalyst indicated that they are all first-order with correlation coefficients $\mathrm{r}^{2}=0.9598 ; 0.9247$; 0.9548 and 0.9614 for the concentrations of $40 \mathrm{mg} / \mathrm{L}, 60 \mathrm{mg} / \mathrm{L}$ and $80 \mathrm{mg} / \mathrm{L}$ and $120 \mathrm{mg} / \mathrm{L} \mathrm{MB}$ respectively (Table 2 ). 


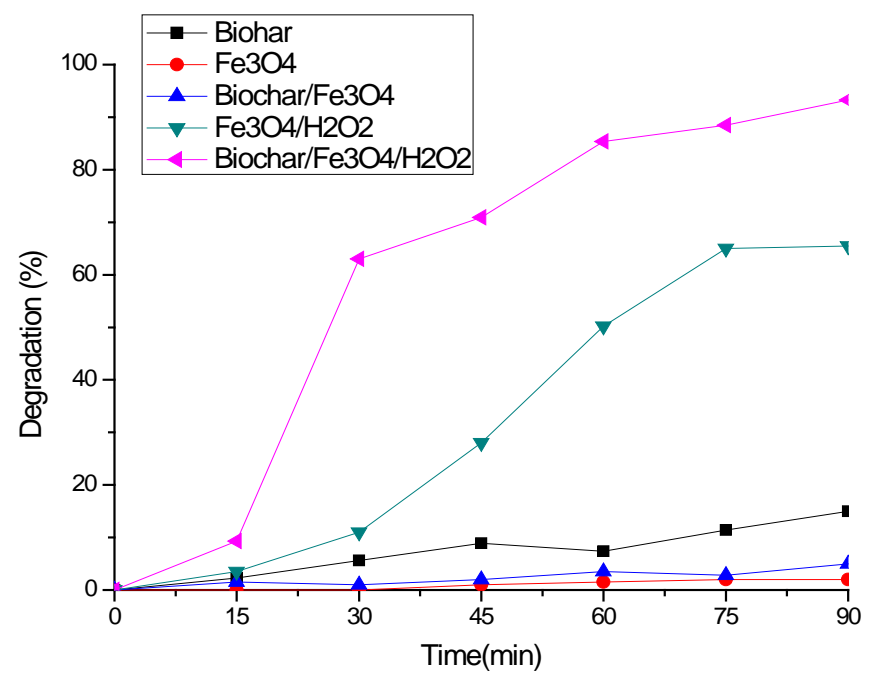

Figures 6. Degradation of methylene blue under different conditions at $\mathrm{pH}=2,80 \mathrm{mg} / \mathrm{L} \mathrm{MB}, 15 \mathrm{mg}$ of the material.

Table 2. MB elimination rate as a function of initial concentration at $90 \mathrm{~min}$ and parameters of kinetic models.

\begin{tabular}{cccccccc}
\hline & \multicolumn{3}{c}{ Zero-order model } & \multicolumn{2}{c}{ First-ordermodel } & \multicolumn{2}{c}{ Second-order model } \\
\hline $\begin{array}{c}\text { Concentration } \\
(\mathrm{mg} / \mathrm{L})\end{array}$ & $\begin{array}{c}\text { Degradation } \\
(\%)\end{array}$ & $\mathrm{K}_{0}\left(\mathrm{~min}^{-1}\right)$ & $\mathbf{R}^{2}$ & $\mathrm{~K}_{1}\left(\mathrm{~min}^{1}\right)$ & $\mathbf{R}^{2}$ & $\mathrm{~K}_{2}\left(\mathrm{~min}^{-1}\right)$ & $\mathrm{R}^{2}$ \\
\hline 40 & 99 & 0.4414 & 0.78 & 0.0546 & 0.96 & 0.0339 & 0.54 \\
60 & 98.6 & 0.678 & 0.77 & 0.0587 & 0.92 & 0.0198 & 0.82 \\
80 & 93.3 & 0.8704 & 0.79 & 0.0433 & 0.95 & 0.0064 & 0.65 \\
120 & 91.4 & 1.1561 & 0.71 & 0.0461 & 0.96 & 0.0084 & 0.51 \\
\hline
\end{tabular}

\section{3. pH Effects}

Studies on the $\mathrm{pH}$ of the medium showed a slight degradation of $\mathrm{MB}$ at $\mathrm{pH} 4$ (Figure 7). This is due to the precipitation of Biochar/ $\mathrm{Fe}_{3} \mathrm{O}_{4}$ in the $\mathrm{MB}$ solution. At $\mathrm{pH}=2$ the degradation is maximal for $15 \mathrm{mg}$ of the catalyst, $0.2 \mathrm{~mL} / \mathrm{L} \mathrm{H}_{2} \mathrm{O}_{2}$, $90 \mathrm{~min}$. The increase in the oxidizing power of the $\mathrm{MB}$ at low $\mathrm{pH}$ (generally between 2 and 4) is attributed to the increase of the oxidizing potential of hydroxide radicals $\left(\mathrm{HO}^{\circ}\right)$ and to a strong dissolution of iron in solution in $\mathrm{MB}$ [40]. The strongly acidic medium is favorable for the stabilization of the hydrogen peroxides which favors the generation of $\mathrm{HO}^{\circ}$ as well as the formation of the metal oxides leading to mineralization of the $\mathrm{MB}$ according to the Equations (1, 2, 3, 4 and 5). Beyond $\mathrm{pH}=2-4$, iron ions $\left(\mathrm{Fe}^{3+}\right.$ and $\left.\mathrm{Fe}^{2+}\right)$ are likely precipitated as solid $\left[\mathrm{Fe}(\mathrm{OH})_{2}\right]$ iron hydroxide and $[\mathrm{FeO}(\mathrm{OH})]$ solid. These precipitations reducing the number of ferrous ions used to catalyze the Fenton reaction and thus induce low catalytic activity [41] [42] [43]. This same phenomenon has been observed on our material which recorded degradation beyond $\mathrm{pH} 2$, from $93.3 \%$ to $88.5 \%$ at $\mathrm{pH}$ 3. At $\mathrm{pH} 4$, we observe a drop in degradation (34.54\%) characterized by an increase in the precipitation of iron hydroxides. 


\subsection{Effects of the Masses}

The mass effect of the catalyst has a very important influence on the degradation of the MB. Indeed the masses of $5 \mathrm{mg}, 10 \mathrm{mg}$ and $15 \mathrm{mg}$ were used in a solution of $\mathrm{MB}(40,60,80$ and $120 \mathrm{mg} / \mathrm{L})$ at $\mathrm{pH} 2,0.2 \mathrm{ml} / \mathrm{L} \mathrm{H}_{2} \mathrm{O}_{2}$ for a maximum contact time of 90 min (Figure 8). The results obtained indicated an increase in the percentage of degradation with the increase of the catalyst mass (Biochar/ $/ \mathrm{Fe}_{3} \mathrm{O}_{4}$ ). That is a degradation ranging from $70 \%$ to $99 \%$ for masses $5 \mathrm{mg}$ to $15 \mathrm{mg}$ of the catalyst. This is explained by the increase of active sites on the surface of the catalyst which is accompanied by the generation of a large amount of iron particles with production of $\mathrm{OH}^{\circ}$ radicals.

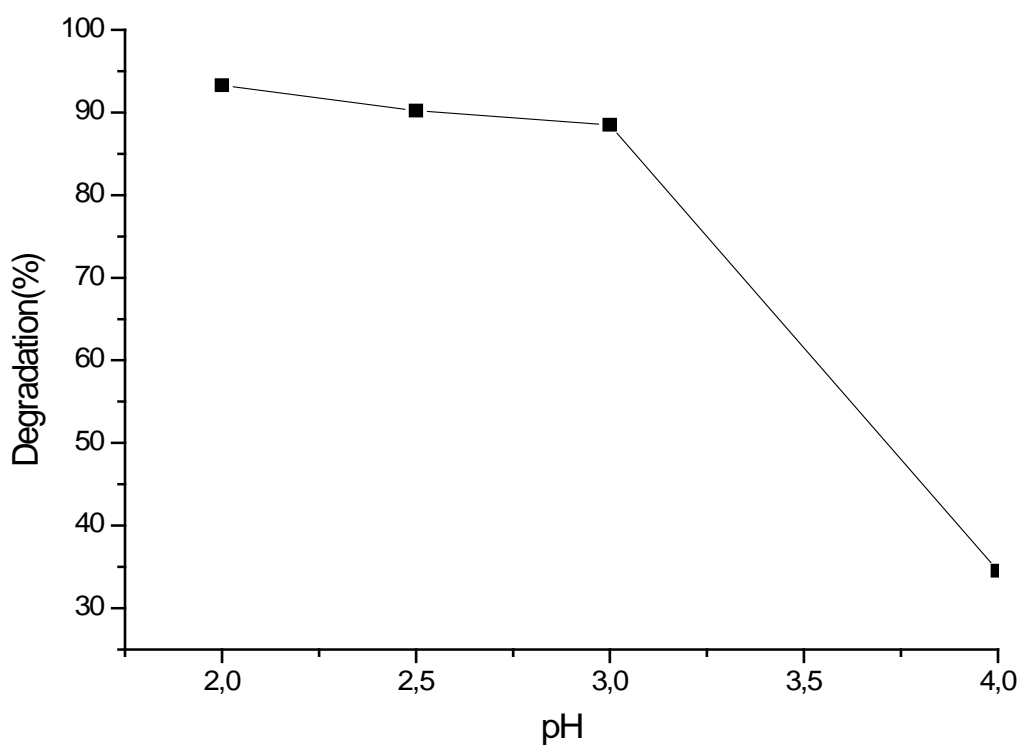

Figure 7. Degradation as a function of $\mathrm{pH}, 80 \mathrm{mg} / \mathrm{L} \mathrm{MB}, 0.2 \mathrm{ml} / \mathrm{L} \mathrm{H}_{2} \mathrm{O}_{2} ; 15 \mathrm{mg}$ catalyst, $90 \mathrm{~min}$, at $25^{\circ} \mathrm{C}$, stirring speed $250 \mathrm{rpm}$.

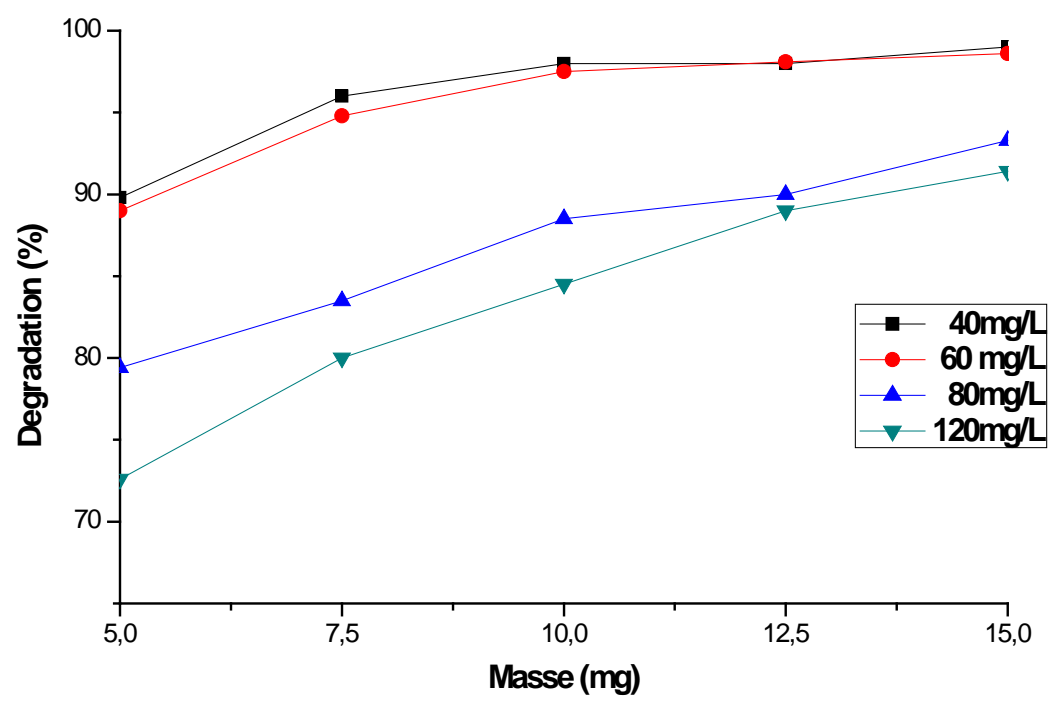

Figure 8. Degradation as a function of mass at different concentrations; $90 \mathrm{~min}$, $\mathrm{pH}=2,0.2 \mathrm{~mL} / \mathrm{L}\left(\mathrm{H}_{2} \mathrm{O}_{2}\right)$ at $25^{\circ} \mathrm{C}$, stirring speed $250 \mathrm{rpm}$. 


\subsection{Concentration Effect of the Pollutant}

The degradation of $\mathrm{MB}$ was also studied according to its concentration. We studied here the concentrations $40 \mathrm{mg} / \mathrm{L}, 60 \mathrm{mg} / \mathrm{L}$ and $80 \mathrm{mg} / \mathrm{L}$ and $120 \mathrm{mg} / \mathrm{L}$. The results of Figure 9, shows a decrease in the degraded amount of MB when increasing the concentration of the pollutant. The maximum elimination is observed at $90 \mathrm{~min}$ with a mass of $15 \mathrm{mg}$ of the catalyst leading to a degradation of $99 \%$; 98.6\%; 93.3\% and $91.4 \%$ for $\mathrm{MB}$ concentrations $40 \mathrm{mg} / \mathrm{L}, 60 \mathrm{~m} / \mathrm{L}, 80 \mathrm{mg} / \mathrm{L}$ and $120 \mathrm{mg} / \mathrm{L}$. This slight decrease in degradation as a function of concentration is probably due to an increase in the number of $\mathrm{MB}$ molecules in the solution for the same amount of hydroxyl radicals formed (responsible for the Fenton reaction). Nevertheless, more than $60 \%$ of elimination is observed for the highest concentration of $120 \mathrm{mg} / \mathrm{L}$ after $90 \mathrm{~min}$ for a small mass of $5 \mathrm{mg}$ of biochar/ $/ \mathrm{Fe}_{3} \mathrm{O}_{4}$. What is encouraging because the concentrations found in textile wastewater is between $10 \mathrm{mg} / \mathrm{L}$ and $250 \mathrm{mg} / \mathrm{L}$ [14]. Regarding Figure 9, the highest degradation percentage was obtained with the highest mass.

\subsection{Effect of Stirring Time}

The influence of contact time has been studied for different catalyst masses ( 5 $\mathrm{mg}, 10 \mathrm{mg}$ and $15 \mathrm{mg}$ ) of 15 to $90 \mathrm{~min}$ (Figure 10). The results of Figure show an increase in degradation as a function of mass and stirring time and a decrease when increasing the concentration of MB. Indeed the reaction is slow during the first 15 minutes with degradation less than $20 \%$, and becomes fast as from $30 \mathrm{~min}$. It reaches the maximum at 90 min with a degradation percentage greater than $75 \%$ depending on the masses and the concentration of the dye. This is due to the permanent production of the electrons by the biochar as well as the radicals $\mathrm{HO}^{\circ}$ by the hydrogen peroxide $\left(\mathrm{H}_{2} \mathrm{O}_{2}\right)$ in the medium as a function of the time, which increases the rate of the reaction of catalysis. The longer the stirring time, the more electrons and radicals $\mathrm{HO}^{\circ}$ are produced and the greater the degradation.

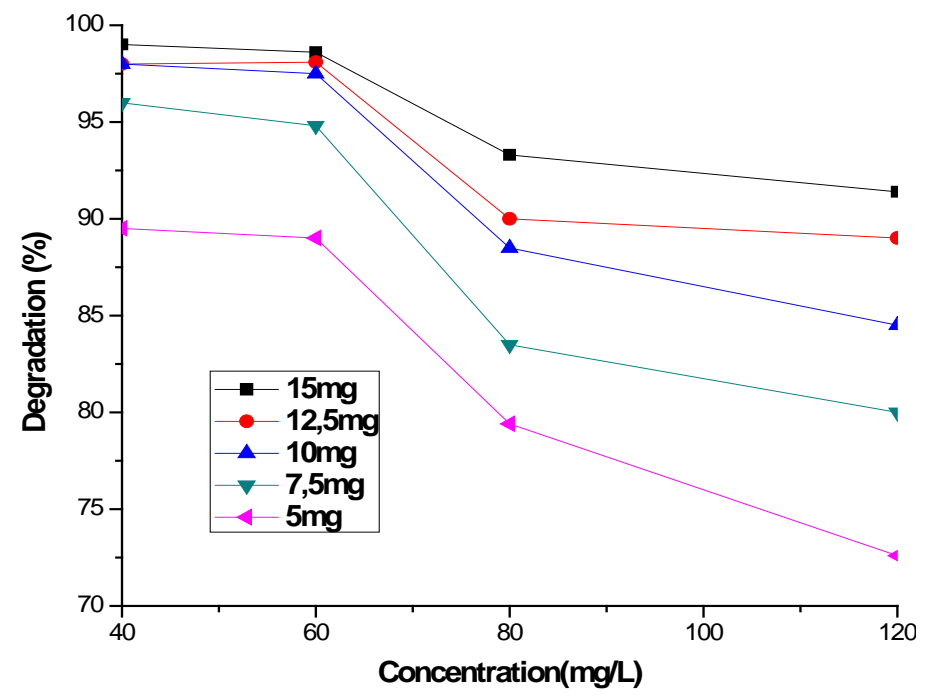

Figure 9. Degradation as a function of $\mathrm{MB}$ concentration at different catalyst masses, $90 \mathrm{~min}, \mathrm{pH}=2 ; 0.2 \mathrm{~mL} / \mathrm{L}\left(\mathrm{H}_{2} \mathrm{O}_{2}\right)$ at $25^{\circ} \mathrm{C}$, stirring speed $250 \mathrm{rpm}$. 


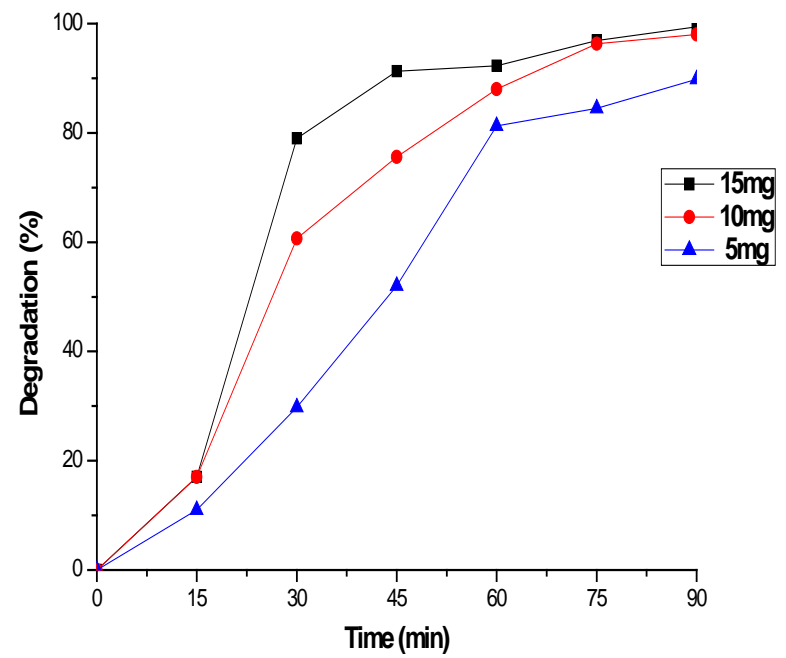

(a)

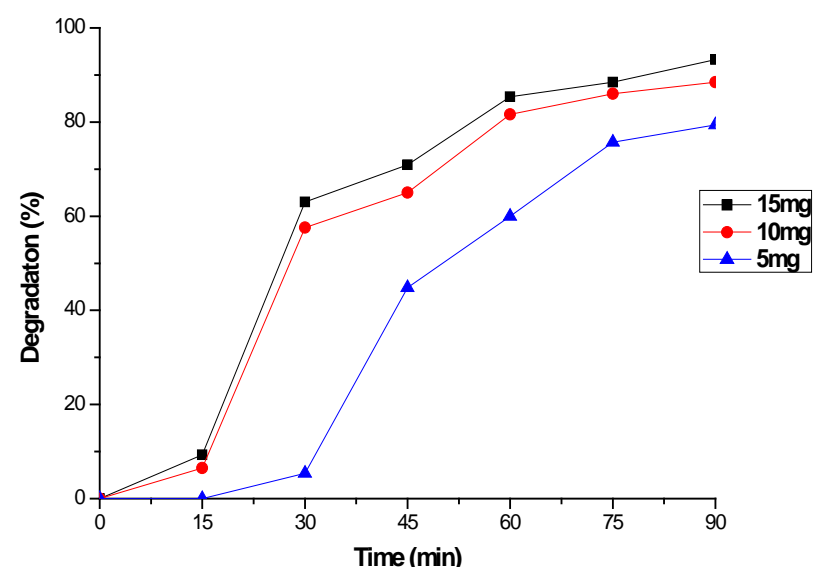

(c)

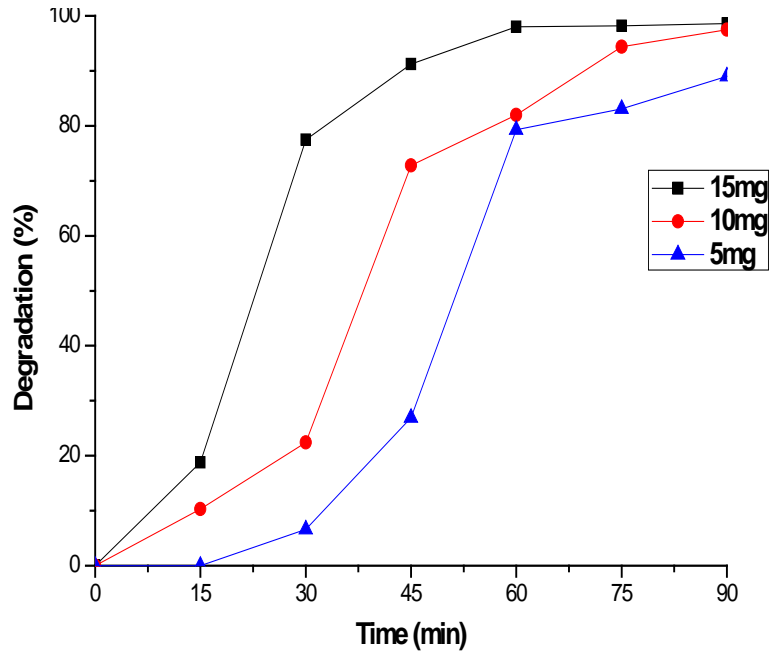

(b)

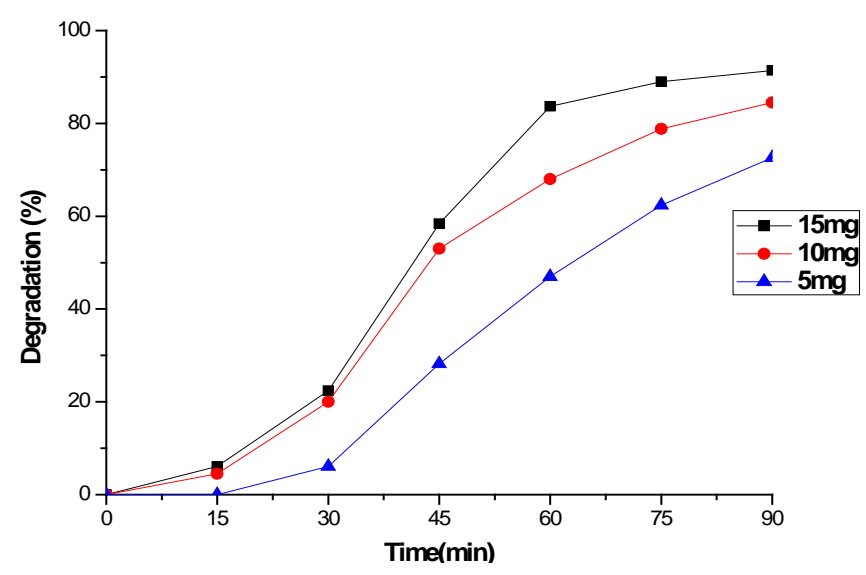

(d)

Figures 10. Degradation as a function of the reaction time at different masses for concentrations of (a) $40 \mathrm{mg} / \mathrm{L}$; (b) $60 \mathrm{mg} / \mathrm{L}$; (c) $80 \mathrm{mg} / \mathrm{L}$; and (d) $120 \mathrm{mg} / \mathrm{L} \mathrm{BM}, \mathrm{pH}=2 ; 0.2 \mathrm{ml} / \mathrm{L} \mathrm{H}_{2} \mathrm{O}_{2}$ at $25^{\circ} \mathrm{C}$, stirring speed $250 \mathrm{rpm}$.

\subsection{Uv-Vis Spectra of Degradation of Methylene Blue as a Function of Time}

The recording of the Uv-vis spectrum in the region $200-800 \mathrm{~nm}$, of $80 \mathrm{mg} / \mathrm{L}$ methylene blue (Figure 11), indicates a progressive decrease of the wavelength peaks $293 \mathrm{~nm}$ and $661 \mathrm{~nm}$ as a function of the contact time. The disappearance of the bands is obtained at a maximum time of $90 \mathrm{~min}$ in $15 \mathrm{mg} / \mathrm{L}$ of the catalyst, and $0.2 \mathrm{ml} / \mathrm{L}$ of $\mathrm{H}_{2} \mathrm{O}_{2}$. The decline in peaks around $293 \mathrm{~nm}$ is evidence of the destruction of the aromatic ring and heteropolyaromatic linkages of MB. Similarly, the decrease in the intensity of the band around $661 \mathrm{~nm}$ is due to the destruction of the thiazine group responsible for the blue coloring of MB [42]. Thus the degradation of methylene blue by homogeneous Fenton using magnetic biochar is evidenced.

\subsection{Stability and Reusability of the Catalyst}

The stability and reusability of the material is an important factor in catalysis. 
Thus we repeated four times the degradation of methylene blue by the same catalyst. After use, the catalyst was recovered by simple magnetic filtration, washed with distilled water and reused for three cycles (Figure 12). This reuse of biochar $/ \mathrm{Fe}_{3} \mathrm{O}_{4}(15 \mathrm{mg})$ was carried out in a solution of $80 \mathrm{mg} / \mathrm{L}(\mathrm{MB}), \mathrm{pH}=2,0.2$ $\mathrm{ml} / \mathrm{L} \mathrm{H}_{2} \mathrm{O}_{2}$ and at $90 \mathrm{~min}$ of stirring. We see the same degradation of methylene blue with no loss of the catalyst activity during the first two cycles and a slight loss of activity in the third cycle and four. This gives us information on the stability of our material (biochar $/ \mathrm{Fe}_{3} \mathrm{O}_{4}$ ) for two cycles.

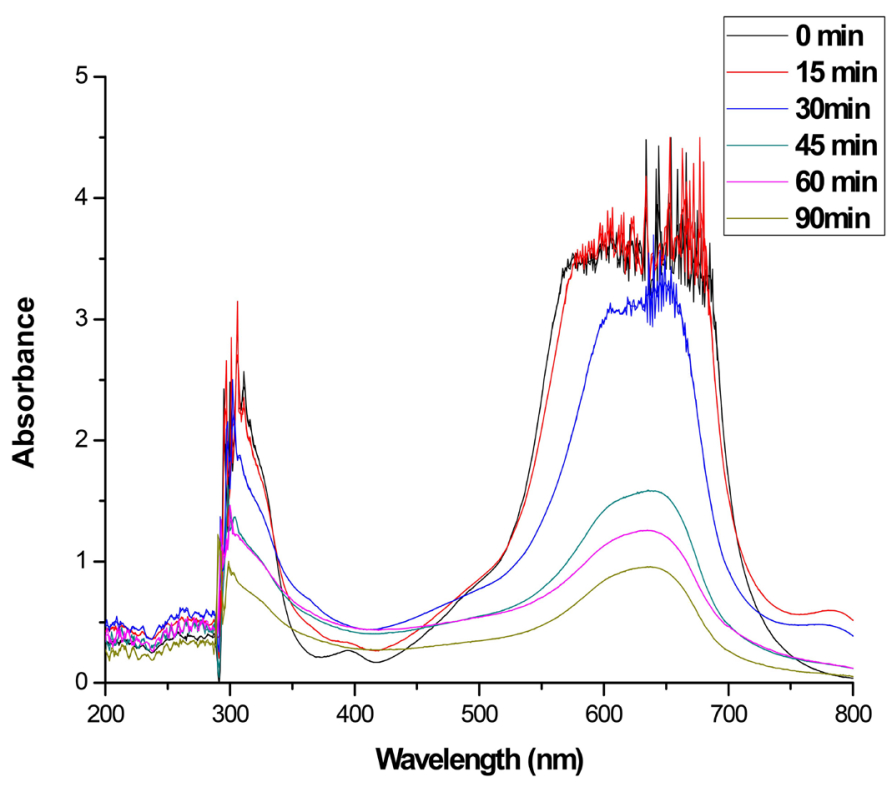

Figure 11. Uv-screw spectral variation of $80 \mathrm{mg} / \mathrm{L}$ of $\mathrm{MB}$ in the degradation process as a function of contact time, in the presence of $15 \mathrm{mg} / \mathrm{L}$ of Biochar $/ \mathrm{Fe}_{3} \mathrm{O}_{4}, 0.2 \mathrm{ml} / \mathrm{L} \mathrm{H}_{2} \mathrm{O}_{2}$, at $25^{\circ} \mathrm{C}$ and $\mathrm{pH}=2$.

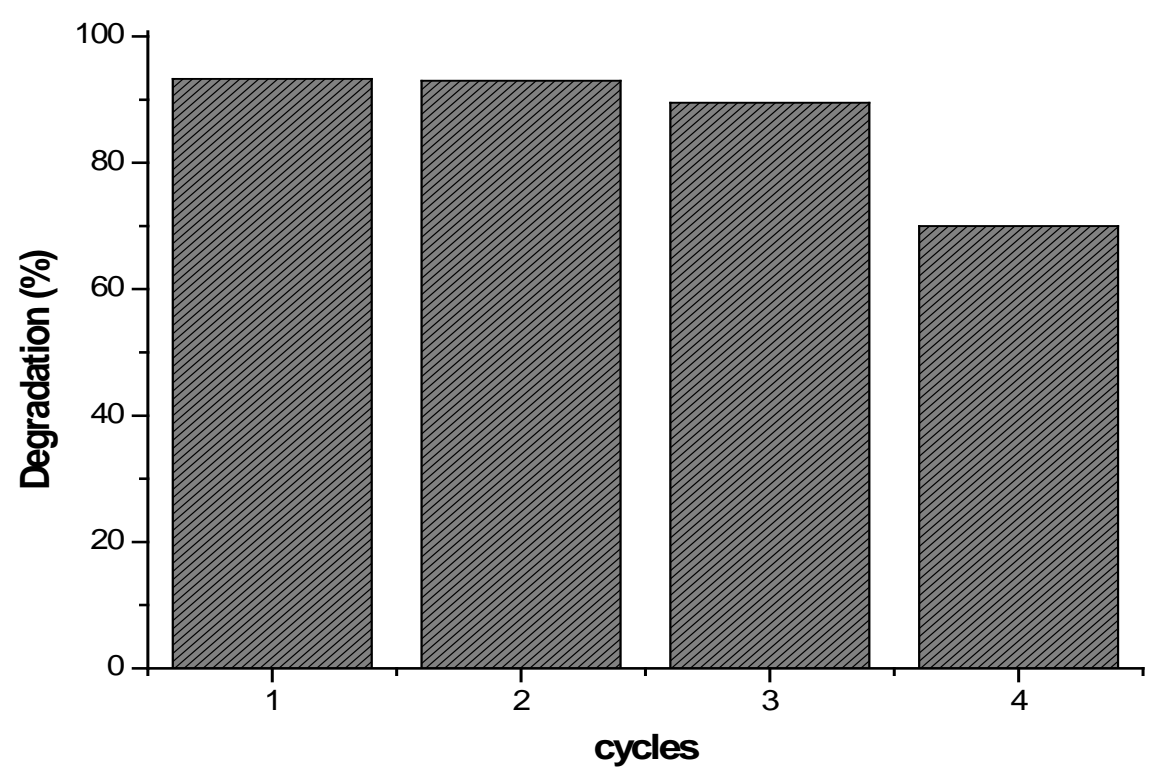

Figure 12. Four cycles of MB degradation by biochar $/ \mathrm{Fe}_{3} \mathrm{O}_{4}$. 


\section{Conclusion}

Biochar $/ \mathrm{Fe}_{3} \mathrm{O}_{4}$ was prepared by a simple method (Co-precipitation) using a biochar based on banana peel and iron chlorides as precursors. The analysis made on these materials showed a better dispersion of the magnetite particles on the surface of the biochar with a yield of 3.54\% iron. Biochar $/ \mathrm{Fe}_{3} \mathrm{O}_{4}$ was found to be very useful for the degradation of methylene blue in aqueous media by heterogeneous Fenton. The use of $\mathrm{H}_{2} \mathrm{O}_{2}(0.2 \mathrm{ml} / \mathrm{L})$ as an oxidizing agent greatly favored the process, from a degradation of less than $5 \%$ (without $\mathrm{H}_{2} \mathrm{O}_{2}$ ) to more than $90 \%$ (in the presence of $\mathrm{H}_{2} \mathrm{O}_{2}$ ) during $90 \mathrm{~min}$ of stirring, $15 \mathrm{mg}$ of the catalyst and at $\mathrm{pH}$ 2. The recovery of the catalyst by magnetization allowed the reusability without prior treatment in the Fenton process.

\section{Acknowledgements}

Authors gratefully acknowledge the technical support of the Laboratory of Applied Organic Chemistry, Analysis and Environmental Unit, Faculty of Science Semlalia, University Caddy Ayyad of Marrakech in Morocco.

\section{Conflicts of Interest}

The authors declare no conflicts of interest regarding the publication of this paper.

\section{References}

[1] Reza, K.M., Kurny, A. and Gulshan, F. (2016) Photocatalytic Degradation of Methylene Blue by Magnetite $+\mathrm{H}_{2} \mathrm{O}_{2}+\mathrm{UV}$ Process. International Journal of Environmental Science and Development, 7, 325-329. https://doi.org/10.7763/IJESD.2016.V7.793

[2] Kpinsoton, G.M.R. (2019) Elaboration de catalyseurs à base de charbon actifs et de latérites pour la dégradatin du bleu de méthylène par procédé fenton hétérogène. Thèse de Doctorat de l'Université 2iE, Burkina Faso, 173 p.

[3] Andreozzi, R., Caprio, V., Insola, A. and Marotta, R. (1999) Advanced Oxidation Processes (AOP) for Water Purification and Recovery. Catalysis Today, 53, 51-59. https://doi.org/10.1016/S0920-5861(99)00102-9

[4] Milan-Segovia, N., Wang, Y., Cannon, F.S., Voigt, R.C. and Furness, J.C. (2007) Comparison of Hydroxyl Radical Generation for Various Advanced Oxidation Combinations as Applied to Foundries. Ozone. Science and Engineering, 29, 461-471. https://doi.org/10.1080/01919510701615433

[5] Zhou, L.C., Shao, Y.M., Liu, J.R., Ye, Z.F., Zhang, H., Ma, J.J., Jia, Y., Gao, W.J. and Li, Y.F. (2014) Preparation and Characterization of Magnetic Porous Carbon Microspheres for Removal of Methylene Blue by a Heterogeneous Fenton Reaction. Applied Materials and Interfaces, 6, 7275-7285. https://doi.org/10.1021/am500576p

[6] Gashtasbi, F., Yengejeh, R.J. and Babaei, A.A. (2018) Photocatalysis Assisted by Activated-Carbon-Impregnated Magnetite Composite for Removal of Cephalexin from Aqueous Solution. Korean Journal of Chemical Engineering, 35, 1726-1734.

[7] Madrakian, T., Afkhami, A., Mahmood-Kashani, H. and Ahmadi, M. (2012) Adsorption of Some Cationic and Anionic Dyes on Magnetite Nanoparticles-Modified 
Activated Carbon from Aqueous Solutions: Equilibrium and Kinetics Study. Journal of Iranian Chemical Society, 10, 481-489.

https://doi.org/10.1007/s13738-012-0182-4

[8] Hu, X., Ding, Z., Zimmerman, A.R., Wang, S. and Gao, B. (2015) Batch and Column Sorption of Arsenic onto Iron-Impregnated Biochar Synthesized through Hydrolysis. Water Research, 68, 206-216. https://doi.org/10.1016/j.watres.2014.10.009

[9] Trakal, L., Veselska, V., Safarık, I., Vitkova, M., Cihalova, S. and Komarek, M. (2016) Lead and Cadmium Sorption Mechanisms on Magnetically Modified Biochars. Bioresource Technology, 203, 318-324. https://doi.org/10.1016/j.biortech.2015.12.056

[10] Zhang, H., Xue, G., Chen, H. and Li, X. (2018) Magnetic Biochar Catalyst Derived from Biological Sludge and Ferricsludge Using Hydrothermal Carbonization: Preparation, Characterization and Its Circulation in Fenton Process for Dyeing Wastewater Treatment. Chemosphere, 191, 64-71. https://doi.org/10.1016/j.chemosphere.2017.10.026

[11] Yuan, L. (2017) Magnetically Recoverable $\mathrm{Fe}_{3} \mathrm{O}_{4}$-Modified Bentonite as a Heterogeneous Catalyst of $\mathrm{H}_{2} \mathrm{O}_{2}$ Activation for Efficient Degradation of Methyl Orange. Polish Journal of Environmental Studies, 26, 2355-2361. https://doi.org/10.15244/pjoes/69936

[12] Fayazi, M., Taher, M.A., Afzali, D. and Mostafavi, A. (2016) Enhanced Fenton-Like Degradation of Methylene Blue by Magnetically Activated Carbon/Hydrogen Peroxide with Hydroxylamine as Fenton Enhancer. Journal of Molecular Liquids, 216, 781-787. https://doi.org/10.1016/j.molliq.2016.01.093

[13] Monika, J., Mithilesh, Y., Tomas, K., Manu, L., Vinod, K.G. and Mika, S. (2018) Development of Iron Oxide/Activated Carbon Nanoparticle Composite for the Removal of $\mathrm{Cr}(\mathrm{VI}), \mathrm{Cu}(\mathrm{II})$ and $\mathrm{Cd}(\mathrm{II})$ Ions from Aqueous Solution. Water Resources and Industry, 20, 54-74. https://doi.org/10.1016/j.wri.2018.10.001

[14] Zhou, W., Rajic, L., Chen, L., Kou, K.K., Ding, Y.N., Meng, X.X., et al. (2019) Activated Carbon as Effective Cathode Material in Iron-Free Electro-Fenton Process: Integrated $\mathrm{H}_{2} \mathrm{O}_{2}$ Electrogeneration, Activation, and Pollutants Adsorption. Electrochimica Acta, 296, 317-326. https://doi.org/10.1016/j.electacta.2018.11.052

[15] Wang, F.F., Yu, X.L., Ge, M.F., Wu, S.J., Guan, J., Tang, J.W., Wu, X. and Ritchie, R.O. (2019) Facile Self-Assembly Synthesis of $\mathrm{g}-\mathrm{Fe}_{2} \mathrm{O}_{3} / \mathrm{Graphene}$ Oxide for Enhanced Photo-Fenton Reaction. Environmental Pollution, 248, 229-237. https://doi.org/10.1016/j.envpol.2019.01.018

[16] Hu, X.J., Zhao, Y.L., Wang, H., Tan, X.F., Yang, Y.X. and Liu, Y.G. (2017) Efficient Removal of Tetracycline from Aqueous Media with a $\mathrm{Fe}_{3} \mathrm{O}_{4}$ Nanoparticles@Graphene Oxide Nanosheets Assembly. International Journal of Environmental Research and Public Health, 14, 1495. https://doi.org/10.3390/ijerph14121495

[17] Huaccallo, Y., Álvarez-Torrellas, S., Marín, M.P., Gil, M.V., et al. (2019) Magnetic $\mathrm{Fe}_{3} \mathrm{O}_{4} /$ Multi-Walled Carbon Nanotubes Materials for a Highly Efficient Depletion of Diclofenac by Catalytic Wet Peroxideoxidation. Environmental Science and Pollution Research, 26, 22372-22388.

[18] Mian, M.M. and Liu, G.J. (2018) Recent Progress in Biochar-Supported Photocatalysts: Synthesis, Role of Biochar, and Applications. Royal Society of Chemistry, 8 , 14237-14248. https://doi.org/10.1039/C8RA02258E

[19] Klüpfel, L., Keiluweit, M., Kleber, M. and Sander, M. (2014) Redox Properties of Plant Biomass Derived Black Carbon (Biochar). Environmental Science \& Technology, 48, 5601-5611. https://doi.org/10.1021/es500906d 
[20] Saquing, J.M., Yu, Y-H. and Chiu, PC. (2016) Wood-Derived Black Carbon (Biochar) as a Microbial Electron Donor and Acceptor. Environmental Science and Technology Letters, 3, 62-66.

[21] Shalini, G. and Saima, H.K. (2016) Removal of Methylene Blue from Waste Water Using Banana Peel as Adsorbent. International Journal of Science, Environment, 5 , 3230-3236.

[22] Kakavandi, B., Jafari, A.J., Kalantary, R.R., Nasseri, S., Ameri, A. and Esrafily, A. (2013) Synthesis and Properties of $\mathrm{Fe}_{3} \mathrm{O}_{4}$-Activatedcarbon Magnetic Nanoparticles for Removal of Aniline from Aqueous Solution: Equilibrium, Kinetic and Thermodynamic Studies. Iranian Journal of Environmental Health Sciences \& Engineering, 10, 1-9.

[23] Zhang, F., Wang, X., Ji, X. and Ma, L. (2016) Efficient Arsenate Removal by Magnetite-Modified Water Hyacinth Biochar. Environmental Pollution, 216, 575-583.

[24] Tu, Y.T., Peng, Z.P., Xu, P.Z., Lin, H.J., Wu, X.N., Yang, L.X. and Huang, J.C. (2017) Characterization and Application of Magnetite Iochars from Satalk by Pyrolysis and Hydrothermal Traitment. Bioressources, 12, 1077-1089.

https://doi.org/10.15376/biores.12.1.1077-1089

[25] Liu, S., Ma, C., Ma, M.-G. and Xu, F. (2019) Magnetic Nanocomposite Adsorbents. In: Micro and Nanotechnologies. Micro and Nano Technologies, Elsevier, 295-316. https://doi.org/10.1016/B978-0-12-814132-8.00013-7

[26] Kim, J.R., Santiano, B., Kim, H. and Kan, E. (2013) Heterogeneous Oxidation of Methylene Blue with Surface-Modified Iron-Amended Activated Carbon. American Journal of Analytical Chemistry, 4, 115-122. https://doi.org/10.4236/ajac.2013.47A016

[27] Nasrollahpoura, A. and Moradia, S.E. (2015) Photochemical Degradation of Methylene Blue Bymetal Oxide-Supported Activated Carbon Photocatalyst. Desalination and Water Treatment, 57, 8854-8862. https://doi.org/10.1080/19443994.2015.1035675

[28] Khalil, M.I. (2015) Co-Precipitation in Aqueous Solution Synthesis of Magnetite Nanoparticles Using Iron(III) Salts as Precursors. Arabian Journal of Chemistry, 8, 279-284. https://doi.org/10.1016/j.arabjc.2015.02.008

[29] Suryawanshi, P.L., Sonawane, S.H., Bhanvase, B.A., et al. (2018) Synthesis of Iron Oxide Nanoparticlesin a Continuous Flow Spiral Microreactorand Corning Advanced Flowreactor. Green Processing and Synthesis, 7, 1-11.

https://doi.org/10.1515/gps-2016-0138

[30] Teguh, E.S., Oktaviana, D.I.P., Abu, M.N.H. and Miftahul, A. (2016) The Modification of Carbon with Iron Oxide Synthesized in Electrolysis Using the Arc Discharge Method. Materials Science and Engineering, 176, 1-6.

[31] Pawlyta, M., Rouzaud, J.-N. and Duber, S. (2015) Raman Microspectroscopy Characterization of Carbon Blacks: Spectral Analysis and Structural Information. Carbon, 84, 479-490. https://doi.org/10.1016/j.carbon.2014.12.030

[32] Abdoul, N.R., Hambate, G.V., Dayirou, N., Abdoul, W., Abdelaziz, B. and Abdelrani, Y. (2018) Development of Porosity of Low Cost Activated Carbon from Post-Consumer Plastics and Lignocellulosic Waste Materials Using Physico-Chemical Activation. Global Journal of Science Frontier Research B: Chemistry, 18, No. 2.

[33] Nanda, S.S., Kim, M.J., Yeom, K.S., An, S.S.A., Ju, H. and Yi, D.K. (2016) Raman Spectrum of Graphene with Its Versatile Future Perspectives. Trends in Analytical Chemistry, 80, 125-131. https://doi.org/10.1016/j.trac.2016.02.024 
[34] Abdoul, N.R., Abdellaziz, B., Isaac, B.N., Ketcha, J.M., Abdelrani, Y. (2015) Composite Activated Carbon from Synthetic Plastics and Lignocellulosic Waste Materials. International Research Journal of Natural and Applied Sciences, 2, 20-32.

[35] Jiang, J.Z., Zou, J., Zhu, L.H., Huang, L., Jiang, H.P. and Zhang, Y.X. (2011) Degradation of Methylene Blue with $\mathrm{H}_{2} \mathrm{O}_{2}$ Activated by Peroxidase-Like $\mathrm{Fe}_{3} \mathrm{O}_{4}$ Magnetic Nanoparticles. Journal of Nanoscience and Nanotechnology, 11, 4793-4799. https://doi.org/10.1166/jnn.2011.4192

[36] Kwon, J.H., Wilson, L.D. and Sammynaiken, R. (2014) Synthesis and Characterization of Magnetite and Activated Carbonbinary Composites. Synthetic Metals, 197, 8-17. https://doi.org/10.1016/j.synthmet.2014.08.010

[37] Amin, M.T., Alazba, A.A. and Shafiq, M. (2017) Removal of Copper and Lead using Banana Biochar in Batch Adsorption Systems: Isotherms and Kinetic Studies. Arabian Journal for Science and Engineering, 43, 5711-5722.

https://doi.org/10.1007/s13369-017-2934-Z

[38] Silva, V.A.J., Andrale, P.L., Silva, M.P.C., Bustamante, A., Luis, D.S.V. and Aguiar, J.A. (2013) Synthesis and Characterization of $\mathrm{Fe}_{3} \mathrm{O}_{4}$ Nanoparticles Coated with $\mathrm{Fu}$ can Polysaccharides. Journal of Magnetism and Magnetic Materials, 343, 138-143. https://doi.org/10.1016/j.jmmm.2013.04.062

[39] Keyhanian, F., Shariati, S., Faraji, M. and Hesabi, M. (2016) Magnetite Nanoparticles with Surface Modification for Removal of Methyl Violet from Aqueous Solutions. Arabian Journal of Chemistry, 9, S348-S354. https://doi.org/10.1016/j.arabjc.2011.04.012

[40] Qin, Q.D., Liu, Y.H., Li, X.C., Sun, T. and Xu, Y. (2018) Enhanced Heterogeneous Fenton-Like Degradation of Methylene Blue by Reduced $\mathrm{CuFe}_{2} \mathrm{O}_{4}$. Royal Society of Chemistry, 8, 1071-1077. https://doi.org/10.1039/C7RA12488K

[41] Wu, K.Q., Xie, Y., Zhao, J. and Hidaka, H. (1999) Photo-Fenton Degradation of a Dye under Visible Light Irradiation. Journal of Molecular Catalysis A: Chemical, 144, 77-84. https://doi.org/10.1016/S1381-1169(98)00354-9

[42] Zaviska, F., Drogui, P., Mercier, G. and Blais, J.-F. (2009) Procédés d'oxydation avancée dans le traitement des eaux et des effluents industriels: Application à la dégradation des polluants réfractaires. Revue des sciences de l'eau, 22, 535-564. https://doi.org/10.7202/038330ar

[43] Ahmad, R.Y., Hasti, D. and Masomeh, D. (2015) Degradation of Phenol with Using of Fenton-Like Processes from Water. Iranian Journal of Health, Safety \& Environment, 2, 325-329. 